\title{
Incidence of venous thromboembolism and hemorrhage related safety studies of preoperative anticoagulation therapy in hip fracture patients undergoing surgical treatment: a case-control study
}

\author{
Zhongdi Liu, Na Han, Hailin Xu*, Zhongguo Fu, Dianying Zhang, Tianbing Wang and Baoguo Jiang*
}

\begin{abstract}
Background: Venous thromboembolism is a common postoperative complication following orthopedic surgeries, with morbid and potentially fatal consequences. Perioperative low-molecular-weight heparin (LMWH) therapy can reduce the incidence of venous thromboembolism, but may also increase the risk of bleeding complications. Current literature reflects the need to balance the improved efficacy of early initiating prophylaxis with increased risk of perioperative bleeding. The purpose of this study was to compare the effectiveness and hemorrhage related safety of preoperative versus postoperative LMWH therapy for prevention of deep venous thrombosis (DVT) and pulmonary embolism (PE) in hip fracture patients.
\end{abstract}

Methods: We retrospectively evaluated 222 patients who underwent surgical treatment at Peking University People's Hospital between January 2009 and December 2010. Patients were allocated to two groups, receiving either preoperative or postoperative initiation of LMWH therapy for venous thromboembolism prophylaxis. Preoperative anticoagulation therapy was initiated 1-12 days prior to surgery (133 patients), and postoperative anticoagulation therapy was initiated $12 \mathrm{~h}$ after completion of surgery (89 patients). The preoperative group was further subdivided into four subgroups according to the time of initiation of therapy: 1-3 days before surgery (group A, 54 patients), 4-6 days before surgery (group B, 57 patients), 7-9 days before surgery (group C, 15 patients), and 10-12 days before surgery (group D, 7 patients). Occurrences of DVT, PE, adverse drug effects, intraoperative and postoperative bleeding were recorded, along with concentrations of preoperative and postoperative hemoglobin and length of hospital stay. The above parameters were compared between groups. (Continued on next page)

\footnotetext{
* Correspondence: hailinxu66@qq.com; jiangbaoguo@vip.sina.com Department of Trauma and Orthopedics, People's Hospital, Peking University, South Xizhimen Street No.11, Xicheng District, 100044 Beijing, China
} 
(Continued from previous page)

Results: Among recipients of preoperative anticoagulation therapy, two patients developed postoperative PE $(1.5 \%)$, one patient developed DVT $(0.75 \%)$. In the group receiving postoperative initiation of anticoagulation therapy, one patient each developed PE and DVT (1.1\%, $1.1 \%)$. There was no difference in the occurrence of PE and DVT between the two groups ( $P>0.05$, Chi-square tests). We identified the incidences of major bleeding, minor bleeding, and intraspinal hematoma after spinal anesthesia, which were $0 \% / 0 \%, 3.76 \% / 3.37 \%$, and $0 \% / 0 \%$, respectively in preoperative and postoperative anticoagulation groups. There was no significant difference in the incidence of bleeding complications between patients receiving preoperatively initiated LMWH with patients receiving postoperatively initiated $L M W H$. Spinal anesthesia was administered to 168 patients, with no cases of postoperative intraspinal hematoma.

Conclusions: Preoperative anticoagulation therapy with LMWH may not increase intraoperative or postoperative blood loss, or the rate of intraspinal hematoma after spinal anesthesia, but also does not significantly reduce the risk of postoperative DVT or PE, compared to postoperative initiation.

Keywords: Hip fracture, Low-molecular-weight heparin, Prophylaxis, Deep vein thrombosis, Pulmonary embolism

\section{Background}

Surgical intervention is the most common form of treatment for hip fractures. Surgeries like total hip arthroplasty and hip fracture fixation often lead to postoperative venous thromboembolism (VTE), associated with high mortality rates $[1,2]$. For patients undergoing surgery for hip fracture, the latest guidelines for prevention of deep venous thrombosis (DVT) by the American College of Chest Physicians (ACCP) (2012, 9th edition) recommend initiation of routine subcutaneous low-molecular-weight heparin (LMWH) therapy either from at least $12 \mathrm{~h}$ before surgery, or at least $12 \mathrm{~h}$ after surgery (two to four hours after removal of the epidural catheter) $[2,3]$. Perioperative LMWH therapy, although useful for preventing VTE, may increase the risk of intraoperative and postoperative bleeding [4]. The guidelines do not provide any comparisons of effectiveness and safety between preoperative and postoperative initiation of LMWH therapy. Hull et al. [5] performed a literature review and found that the timing of initiation of LMWH therapy significantly affected the effectiveness of DVT prophylaxis. In another review, Perka [6] reported no difference in the effectiveness of preoperative versus postoperative initiation of anticoagulation therapy for DVT prophylaxis. It is important to take into consideration both effectiveness and safety of the regimes when determining the optimal time for initiation of anticoagulation therapy in patients undergoing orthopedic surgeries for which DVT prophylaxis is indicated $[7,8]$. Preoperative initiation of anticoagulation therapy can effectively reduce the risk of DVT, but, on the other hand, may increase the risk of intraoperative and postoperative bleeding $[9,10]$. Further, among patients receiving spinal anesthesia, preoperative initiation of anticoagulation therapy may increase the risk of intraspinal hematoma. Postoperative initiation of anticoagulation therapy reduces the likelihood of bleeding complications, but may not be as effective as preoperative regimen in preventing DVT. Thus, it is not surprising that consensus on optimal time for initiation of anticoagulation therapy is yet to be reached [11, 12]. Regardless of the drug used, benefits (prevention of VTE) and risks (bleeding and intraspinal hematoma) should be taken into account while deciding whether to administer anticoagulation therapy [13]. Such decision making depends on many parameters such as type of drug, drug dosage, timing of drug administration, surgical procedure, medical history, condition of the patient etc. In clinical practice, the timing of initiation of anticoagulation therapy varies widely across geographical region [5, 14]. This retrospective study analyzed outcomes of perioperative anticoagulation therapy in 222 patients who underwent surgery for treatment of femoral neck or intertrochanteric fractures, between January 2009 and December 2010 at Peking University People's hospital, to evaluate the effectiveness and safety of pre- and postoperative initiation of anticoagulation therapy for DVT prophylaxis. As the optimal regimen is uncertain because direct comparisons among different regimens with sufficient large sample sizes are not available, our study may provide a reference in choosing the appropriate methods to prevent the perioperative venous thromboembolism.

\section{Methods \\ Patients}

This study enrolled hip fracture patients who underwent surgical treatment between January 2009 and December 2010 in the Department of Orthopedics and Trauma at Peking University People's Hospital. Study subject selection criteria were determined so as to avoid the influence of known risk factors on outcomes $[15,16]$. The inclusion criteria were: (1) surgical treatment for hip 
fracture, especially total hip arthroplasty; (2) age $>40$ years; (3) weight 40-100 kg; (4) no preoperative signs/ symptoms of DVT such as lower limb swelling, pain, stiffness, superficial venous congestion, or increased skin temperature; (5) no preoperative signs/symptoms of pulmonary embolism (PE) such as dyspnea, chest pain, or cough; and, (6) VTE prophylaxis with LMWH. Patients with multiple fractures, hemorrhagic diseases or other contraindications to anticoagulation therapy (e.g., those taking oral anticoagulants, or platelet inhibitors, experiencing any active bleeding; having history of heparininduced thrombocytopenia, platelet count $<100,000 /$ $\mathrm{mm}^{3}$ etc.) were excluded. As per the ACCP guidelines, all included patients were in the high-risk group for VTE [1]. Occurrences of deep venous thrombosis, pulmonary embolism, adverse drug effects, intraoperative and postoperative bleeding were recorded, along with concentrations of preoperative and postoperative hemoglobin, blood loss, post-surgical wound drainage, duration of surgery and length of hospital stay. The above parameters were compared between groups.

\section{Ethics statement}

Written informed consent was obtained from all participants, and the study was approved by the Ethics Committee of People's Hospital, Peking University. All clinical investigations are conducted according to the principles expressed in the Declaration of Helsinki.

\section{Prevention of VTE}

Study subjects were categorized into two groups according to time of initiation of LMWH therapy - 1) preoperative and 2) postoperative. Patients in both groups received subcutaneous LMWH (Fraxiparine; GlaxoSmithKline, Notre Dame de Bondeville, France), 4100 units daily until discharge. The timing of initiation of therapy was based on respective physician's preference, and not on the preoperative condition of the patient. Preoperative anticoagulation therapy was initiated 1-12 days prior to surgery, and postoperative anticoagulation therapy was initiated $12 \mathrm{~h}$ after completion of surgery. The preoperative group was further subdivided into four subgroups according to the time of initiation of therapy: 1-3 days before surgery (group A), 4-6 days before surgery (group B), 7-9 days before surgery (group C), and 10-12 days before surgery (group D). All study patients were subjected to basic preventive measures, including care to avoid of intraoperative injury to the intima, regular postoperative turning, early functional exercises, and elastic stockings. Drains were removed when the drainage volume got reduced to $<50 \mathrm{~mL} / 24 \mathrm{~h}$. The mean duration of hospitalization was $20 \pm 5$ days in patients who received preoperative anticoagulation therapy and $19 \pm 6$ days in patients receiving only postoperative anticoagulation therapy. Patients were encouraged to walk following discharge in order to reduce the risk of DVT.

\section{Method of anesthesia}

The American Academy of Orthopedic Surgeons (AAOS) guidelines recommend spinal, epidural, or combined spinal-epidural anesthesia for patients undergoing total hip or total knee arthroplasty [17]. Preoperative antithrombotic and antiplatelet therapy is often administered to orthopedic patients to prevent postoperative DVT [18]. Although such prophylactic measures have been reported to increase the risk of intraspinal hematoma, it has also been shown that with appropriate dosage and timing, anticoagulation therapy can prove to be safe and effective in patients undergoing spinal anesthesia [19]. In our study, 168 patients received spinal anesthesia; while 54 patients did not - owing to structural deformity of vertebral column or previous thoracolumbar trauma. Preoperative anticoagulation therapy was not considered as a contraindication to spinal anesthesia.

\section{Effectiveness of LMWH therapy}

Patients in both groups underwent routine preoperative and postoperative blood tests including liver and kidney function tests, and urine tests. Specific investigations for DVT were conducted if any of the patients developed sudden onset of lower limb swelling, pain, numbness, superficial venous congestion, or increase in skin temperature. Investigations for $\mathrm{PE}$ were undertaken if anyone developed dyspnea, chest pain, hemoptysis, or cyanosis. D-dimer levels were also assessed for patients with suspected VTE. Lower limb compression color Doppler ultrasonography and computed tomography pulmonary angiography were performed as needed. Positive imaging findings were mandatory requirements for definitive diagnosis of DVT.

\section{Safety of LMWH therapy}

Medical records of study patients including postoperative wound drainage, drain removal time, volumes of wound bleeding, hematoma formation, and changes in lower limb sensation or muscle strength were reviewed. Preoperative (the day before surgery) and postoperative (the day after surgery) laboratory test results were compared to detect presence of major bleeding, thrombocytopenia, and any significant changes in organ function. Major bleeding was defined as any of the following: decrease in hemoglobin concentration by $20 \mathrm{~g} / \mathrm{L}$ or more within $24 \mathrm{~h}$, need for transfusion of more than 2 units of red blood cells based on change in hemoglobin concentration, evidence of major organ bleeding such as intracranial or gastrointestinal bleeding, intraoperative bleeding needing surgical intervention, or intramuscular bleeding resulting in compartment 
syndrome [20]. All other types of bleeding were classified as minor. Thrombocytopenia was defined as either a reduction in platelet concentration from $>150 \times 10^{19} / \mathrm{L}$ (preoperative) to $<100 \times 10^{19} / \mathrm{L}$ (postoperative), or a $>50 \%$ decrease during postoperative period from a preoperative concentration of $<150 \times 10^{19} / \mathrm{L}$ [21]. Transaminase levels and signs of allergic reactions were also recorded for every study patient.

\section{Statistical analysis}

Pre- and postoperative anticoagulation therapy groups, and subgroups among the recipients of preoperative anticoagulation therapy, were compared using the Chisquare tests and Non-parametric tests. Analyses were performed using Statistical Product and Service Solutions statistical software (Spss19.0). A value of $P<0.05$ was considered statistically significant.

\section{Results}

\section{Patient characteristics}

A total of 222 patients (81 males, 141 females) met the criteria for inclusion, of whom 111 were admitted with femoral neck fractures and 111 with intertrochanteric fractures. The mean age of patients was $75 \pm 8$ (S.D.) years. Among study patients, 81, 30 and 111 underwent total hip arthroplasty, hemi-arthroplasty, and fixation with proximal femoral nail anti-rotation, respectively. 23 patients received combined spinal-epidural anesthesia, while 145 and 54, respectively, were subjected to spinal and general anesthesia. Table 1 shows the group characteristics among recipients of pre- and postoperative anticoagulation therapy. Table 2 depicts patient characteristics in the subgroups with received initiation of anticoagulation therapy 1-3 days before surgery (group A), 4-6 days before surgery (group B), 7-9 days before surgery (group C), and 10-12 days before surgery (group D).

\section{Treatment data}

The mean duration of surgery was $176 \pm 34$ min. Mean blood loss was estimated to be $216 \pm 135 \mathrm{~mL}$, with 15 patients requiring intraoperative blood transfusion and 93 needing postoperative blood transfusion. Mean postsurgical wound drainage, collected from tubes placed according to surgical conventions, amounted to $225 \pm 133$ $\mathrm{mL}$ and mean time till drain removal was 2 days, while mean length of hospital stay was $20 \pm 4$ days.

\section{Incidence of complications}

Among recipients of preoperative anticoagulation therapy, two patients developed postoperative PE, of whom one died and one was successfully treated by thrombolysis. Only one patient developed DVT in the preoperative group, and he was successfully treated with thrombolysis and supportive measures. In the group receiving postoperative initiation of anticoagulation therapy, one patient each developed PE and DVT, both of whom recovered with symptomatic treatment only. There was no difference in the occurrence of PE and DVT between the two groups ( $P>0.05$, Chi-square tests).

In the preoperative group, five patients suffered from minor wound bleeding, indicated by wound ecchymosis and bleeding. In the same group, one patient developed

Table 1 Characteristics of patients who received preoperative and postoperative initiation of anticoagulation therapy

\begin{tabular}{lccc}
\hline Characteristics & $\begin{array}{c}\text { Preoperative anticoagulation group } \\
(n=133)\end{array}$ & $\begin{array}{c}\text { Postoperative anticoagulation group } \\
(n=89)\end{array}$ & $\begin{array}{c}\text { Total } \\
(n=222)\end{array}$ \\
\hline $\begin{array}{l}\text { Basic Information } \\
\text { Age(years), mean } \pm \text { SD }\end{array}$ & $76 \pm 9$ & $73 \pm 14$ & $75 \pm 8$ \\
Gender & & & 0.396 \\
Male & 52 & 29 & 81 \\
Female & 81 & 60 & 141 \\
Body weight (kg), mean \pm SD & $58.87 \pm 11.34$ & $58.76 \pm 10.57$ & $58.83 \pm 11.01$ \\
Body mass index, mean \pm SD & $22.20 \pm 3.58$ & $22.32 \pm 3.80$ & $22.25 \pm 3.50$ \\
Comorbid conditions, $n(\%)$ & & & 0.506 \\
Hypertension & $36(27.06)$ & $20(22.47)$ & $56(25.23)$ \\
Diabetes & $33(24.81)$ & $17(19.10)$ & $50(22.53)$ \\
Congestive heart failure & $5(3.76)$ & $1(1.12)$ & $6(2.70)$ \\
Varicose veins & $4(3.01)$ & $4(4.49)$ & $8(3.60)$ \\
Currently active cancer & $0(0)$ & $0(0)$ & $0(0)$ \\
Paralysis of lower limbs & $7(5.26)$ & $3(3.37)$ & $10(4.5)$ \\
Atrial fibrillation & $11(8.27)$ & $4(4.49)$ & $15(6.76)$ \\
Prior stroke or TIA & $7(5.26)$ & $5(5.62)$ & $12(5.41)$ \\
\hline
\end{tabular}


Table 2 Patients' characteristics according to the time of initiation of preoperative anticoagulation therapy

\begin{tabular}{|c|c|c|c|c|c|c|}
\hline Characteristics & $\begin{array}{l}\text { Group A } \\
(n=54)\end{array}$ & $\begin{array}{l}\text { Group B } \\
(n=57)\end{array}$ & $\begin{array}{l}\text { Group C } \\
(n=15)\end{array}$ & $\begin{array}{l}\text { Group D } \\
(n=7)\end{array}$ & $\begin{array}{l}\text { Total } \\
(n=133)\end{array}$ & $P$ value \\
\hline \multicolumn{7}{|l|}{ Basic Information } \\
\hline Age (years), mean \pm SD & $76 \pm 11$ & $75 \pm 8$ & $76 \pm 8$ & $79 \pm 4$ & $76 \pm 9$ & 0.647 \\
\hline \multicolumn{7}{|l|}{ Gender } \\
\hline Male & 22 & 20 & 7 & 3 & 52 & \\
\hline Female & 32 & 37 & 8 & 4 & 81 & \\
\hline Body weight $(\mathrm{kg})$, mean $\pm \mathrm{SD}$ & $58.31 \pm 11.55$ & $58.96 \pm 12.01$ & $61 \pm 9.96$ & $57.71 \pm 9.36$ & $58.87 \pm 11.34$ & \\
\hline Body mass index, mean $\pm \mathrm{SD}$ & $22.08 \pm 3.94$ & $22.28 \pm 3.68$ & $22.46 \pm 2.71$ & $22.08 \pm 3.94$ & $21.83 \pm 58.10$ & 0.971 \\
\hline \multicolumn{7}{|l|}{ Comorbid conditions, n (\%) } \\
\hline Hypertension & $11(20.37)$ & $13(22.81)$ & $8(53.33)$ & $4(57.14)$ & $36(27.06)$ & \\
\hline Diabetes & $9(16.67)$ & $14(24.56)$ & $7(46.67)$ & $5(71.43)$ & $33(24.81)$ & \\
\hline Congestive heart failure & $3(5.56)$ & $1(1.75)$ & $0(0)$ & $1(14.29)$ & $5(3.76)$ & \\
\hline Varicose veins & $2(3.70)$ & $1(1.75)$ & $1(6.67)$ & $0(0)$ & $4(3.01)$ & \\
\hline Currently active cancer & $0(0)$ & $0(0)$ & $0(0)$ & $0(0)$ & $0(0)$ & \\
\hline Paralysis of lower limbs & $2(3.70)$ & $4(7.02)$ & $1(6.67)$ & $0(0)$ & $7(5.26)$ & \\
\hline Atrial fibrillation & $5(9.26)$ & $4(7.02)$ & $1(6.67)$ & $1(14.29)$ & $11(8.27)$ & \\
\hline Prior stroke or TIA & $2(3.70)$ & $4(7.02)$ & $1(6.67)$ & $0(0)$ & $7(5.26)$ & \\
\hline
\end{tabular}

a suspected allergic skin reaction, characterized by rashes over abdomen and lower limbs, but no change in heart rate or blood pressure. The condition was treated successfully with medication. In the group receiving postoperative anticoagulation therapy only, three patients developed minor wound bleeding, one suffered from suspected heparin-induced thrombocytopenia (successfully treated by platelet transfusion and symptomatic treatment), and one had a mild increase in serum transaminase levels. None of the study patients required discontinuation of LMWH therapy. Spinal anesthesia was administered to 168 patients, with no cases of postoperative intraspinal hematoma (Table 3, Table 4).

\section{Discussion}

Patients undergoing hip fracture surgery are at increased risk of VTE, especially in those with additional risk factors. Without prophylaxis, rate of postoperative VTE can be as high as 40-60\%, with no major differences in rates between Asian and Western countries [1,22]. Chemical prophylaxis in these patients was considered appropriate. In spite of that, bleeding complications was the major concern of surgeons during chemoprophylaxis, and should be considered when deciding on the time of initiation of therapy [23, 24]. A literature review by Dahl et al. [4] found that, among patients undergoing total hip arthroplasty, the dose, administration time (preoperative initiation of $40 \mathrm{mg}$ daily vs. postoperative initiation of 30 mg twice daily) and duration of use of enoxaparin (5-14 days vs. 28-39 days) were not associated with major bleeding events. In the present study, there was no occurrence of major hemorrhagic complications, and only eight cases of wound bruising or oozing, suggesting that administration of LMWH is quite safe. Previous reports have indicated that adverse reactions of LMWH are low, and no serious adverse reactions were observed in this study. One case had a mild elevated aminotransferase level and one had a suspicious allergic reaction, but LMWH was not discontinued in any of these cases. For the patient with a suspicious allergic reaction, no further examinations were taken since the skin rash disappeared after topical drug treatment.

This study included patients at high risk of VTE, who received regular LMWH administration along with adjunct mechanical therapy measures. Preoperative anticoagulation therapy was initiated 1-12 days prior to surgery, as soon as the patient was admitted to hospital, and postoperative anticoagulation therapy was initiated $12 \mathrm{~h}$ after completion of surgery. Drain removal was $3 \mathrm{~h}$ prior to LMWH administration, thus reducing the risk of bleeding during the removal process. DVT and PE diagnosis during anticoagulation treatment were made strictly in accordance with the patient's clinical manifestations and laboratory test results, with suspicious cases undergoing lower limb compression color Doppler ultrasonography or computed tomography pulmonary angiography.

Both ACCP ["Prevention of Venous Thromboembolism in Orthopedic Surgery Patients: Antithrombotic Therapy and Prevention of Thrombosis" (9th edition, 2012)] and AAOS guidelines ["Clinical Practice Guideline on Preventing Venous Thromboembolic Disease in Patients 
Table 3 Surgical and postoperative information, efficacy and safety in patients receiving preoperative and postoperative initiation of anticoagulation therapy

\begin{tabular}{|c|c|c|c|c|}
\hline Characteristics & $\begin{array}{l}\text { Preoperative Anticoagulation group } \\
(n=133)\end{array}$ & $\begin{array}{l}\text { Postoperative anticoagulation group } \\
(n=89)\end{array}$ & $\begin{array}{l}\text { Total } \\
(n=222)\end{array}$ & $P$ value \\
\hline \multicolumn{5}{|l|}{ Surgical information } \\
\hline General anaesthesia, $\mathrm{n}(\%)$ & $37(27.82)$ & $17(19.10)$ & $54(34.32)$ & \\
\hline Surgery time $(\mathrm{min})$, mean $\pm \mathrm{SD}$ & $173 \pm 43$ & $180 \pm 53$ & $176 \pm 34$ & 0.287 \\
\hline Intraoperative bleeding $(\mathrm{mL})$, mean $\pm \mathrm{SD}$ & $208 \pm 183$ & $228 \pm 179$ & $216 \pm 135$ & 0.204 \\
\hline Intraoperative blood transfusion, n (\%) & $9(6.77)$ & $6(6.74)$ & $15(6.76)$ & \\
\hline \multicolumn{5}{|l|}{ Postoperative information } \\
\hline Postoperative blood transfusion, n (\%) & $22(16.54)$ & $13(14.61)$ & $35(15.77)$ & \\
\hline Postoperative drainage $(\mathrm{mL})$, mean $\pm \mathrm{SD}$ & $212 \pm 154$ & $244 \pm 196$ & $225 \pm 133$ & 0.403 \\
\hline Reduction in hemoglobin concentrations ( $g / L)$ & $23 \pm 11$ & $27 \pm 13$ & $25 \pm 14$ & 0.143 \\
\hline Hospital stays(days),mean \pm SD & $20 \pm 5$ & $19 \pm 6$ & $20 \pm 4$ & 0.104 \\
\hline \multicolumn{5}{|l|}{ Efficacy assessment, n (\%) } \\
\hline Symptomatic DVT & $1(0.75)$ & $1(1.1)$ & $2(0.90)$ & \\
\hline Symptomatic PE & $2(1.5)$ & $1(1.1)$ & $3(1.35)$ & \\
\hline \multicolumn{5}{|l|}{ Safety assessment, n (\%) } \\
\hline Major bleeding & $0(0)$ & $0(0)$ & $0(0)$ & \\
\hline Minor bleeding & $5(3.76)$ & $3(3.37)$ & $8(3.60)$ & \\
\hline Thrombocytopenia & $0(0)$ & $1(1.1)$ & $1(0.45)$ & \\
\hline Elevated aminotransferase & $0(0)$ & $1(1.1)$ & $1(0.45)$ & \\
\hline Suspicious allergic reaction & $1(0.75)$ & $0(0)$ & $1(0.45)$ & \\
\hline
\end{tabular}

Undergoing Elective Hip and Knee Arthroplasty" (2011)] recommend anticoagulation therapy for DVT prophylaxis for patients undergoing hip or knee arthroplasty or surgical treatment of hip fractures [2, 17]. The ACCP and AAOS guidelines also suggest LMWH as the preferred agent for DVT prophylaxis [1]. It can be noted that LMWH is the most commonly used drug for the prevention of postoperative DVT in the United States [25]. The most common time of initiation of anticoagulation therapy was reported to be $13-24$ h after surgery (35\%). Mont M [26] highlighted that preoperative initiation of anticoagulation therapy had been based on a theory that ascribe surgical trauma as the principal cause of DVT, and postoperative initiation of prophylaxis might be adequate because DVT usually develops over a prolonged period of time (several days to weeks). They further argued that postoperative initiation of prophylaxis should be favored as it reduced the risks associated with spinal anesthesia and surgery.

Some researchers have recommended against preoperative initiation of anticoagulation therapy under the assumption that it may increase the rate of postoperative intraspinal hematoma in patients receiving spinal anesthesia. Occurrence of spinal cord edema following spinal anesthesia is quite rare $(1: 150000)$, and the risk of spinal hematoma in women undergoing knee arthroplasty is only 1:3600 [23, 27]. Hull et al. performed a meta-analysis of studies on effectiveness and safety of preoperative and postoperative initiation of LMWH therapy in elective hip joint replacement surgery patients. The study found that, among patients undergoing preoperative and postoperative initiation of therapy, the incidence of DVT were $10 \%$ and $15.3 \%$, respectively ( $P$ $=0.02$ ), and, contrary to expectation, the incidence of major bleeding events was lower in patients with preoperative rather than postoperative initiation of therapy (0.9 \% vs $3.5 \%, P=0.01$ ) [24].

Our study did not detect any significant differences in the effectiveness of DVT or PE prevention between initiation of LMWH therapy $\geq 12 \mathrm{~h}$ before surgery and $\geq 12 \mathrm{~h}$ after surgery. No cases of postoperative intraspinal hematoma were detected among the 168 study patients who received spinal anesthesia for total hip arthroplasty or hip fracture fixation surgery. Preoperative initiation of anticoagulation therapy did not increase the risk of intraspinal hematoma. Moreover, no significant differences were detected in terms of intraoperative blood loss, postoperative wound drainage, change in hemoglobin concentration after surgery, and change in hematocrit after surgery among subgroups of patients in whom anticoagulation therapy were initiated 1-3 days, 4-6 days, 7-9 days, and 10-12 days before surgery. 
Table 4 Surgical and postoperative information, efficacy and safety in each subgroup of patients receiving preoperative initiation anticoagulation group

\begin{tabular}{|c|c|c|c|c|c|c|}
\hline Characteristics & $\begin{array}{l}\text { Group A } \\
(n=54)\end{array}$ & $\begin{array}{l}\text { Group B } \\
(n=57)\end{array}$ & $\begin{array}{l}\text { Group C } \\
(n=15)\end{array}$ & $\begin{array}{l}\text { Group D } \\
(n=7)\end{array}$ & $\begin{array}{l}\text { Total } \\
(n=133)\end{array}$ & $\begin{array}{l}P \\
\text { value }\end{array}$ \\
\hline \multicolumn{7}{|l|}{ Surgical information } \\
\hline General anaesthesia, $\mathrm{n}(\%)$ & $14(25.93)$ & $16(28.07)$ & $5(33.33)$ & $2(28.57)$ & $37(27.82)$ & \\
\hline Surgery time $(\mathrm{min})$, mean $\pm \mathrm{SD}$ & $171 \pm 51$ & $175 \pm 38$ & $168 \pm 37$ & $187 \pm 21$ & $173 \pm 43$ & 0.408 \\
\hline Intraoperative bleeding $(\mathrm{mL})$, mean $\pm \mathrm{SD}$ & $210 \pm 89$ & $211 \pm 171$ & $227 \pm 234$ & $192 \pm 142$ & $208 \pm 183$ & 0.805 \\
\hline Intraoperative blood transfusion, n (\%) & $4(7.41)$ & $2(3.51)$ & $2(13.33)$ & $1(14.29)$ & $9(6.77)$ & \\
\hline \multicolumn{7}{|l|}{ Postoperative information } \\
\hline Postoperative blood transfusion, n (\%) & $6(11.11)$ & $9(15.79)$ & $4(26.67)$ & $3(42.86)$ & $22(16.54)$ & \\
\hline Postoperative drainage $(\mathrm{mL})$, mean $\pm \mathrm{SD}$ & $201 \pm 157$ & $203 \pm 149$ & $259 \pm 188$ & $260 \pm 81$ & $212 \pm 154$ & 0.277 \\
\hline Reduction in hemoglobin concentrations ( $g / L)$ & $24 \pm 11$ & $24 \pm 10$ & $18 . \pm 14$ & $15 \pm 10$ & $23 \pm 11$ & 0.375 \\
\hline Hospital stays(days), mean \pm SD & $18 \pm 4$ & $21 \pm 4$ & $24 \pm 7$ & $23 \pm 7$ & $20 \pm 5$ & 0.00 \\
\hline \multicolumn{7}{|l|}{ Efficacy assessment, n (\%) } \\
\hline Symptomatic DVT & $0(0)$ & $1(1.75)$ & $0(0)$ & $0(0)$ & $1(0.75)$ & \\
\hline Symptomatic PE & $1(1.85)$ & $0(0)$ & $1(6.67)$ & $0(0)$ & $2(1.50)$ & \\
\hline \multicolumn{7}{|l|}{ Safety assessment, n (\%) } \\
\hline Major bleeding & $0(0)$ & $0(0)$ & $0(0)$ & $0(0)$ & $0(0)$ & \\
\hline Minor bleeding & $1(1.85)$ & $0(0)$ & $2(13.3)$ & $2(28.6)$ & $5(3.76)$ & \\
\hline Thrombocytopenia & $0(0)$ & $0(0)$ & $0(0)$ & $0(0)$ & $0(0)$ & \\
\hline Elevated aminotransferase & $0(0)$ & $0(0)$ & $0(0)$ & $0(0)$ & $0(0)$ & \\
\hline Suspicious allergic reaction & $0(0)$ & $1(1.75)$ & $0(0)$ & $0(0)$ & $1(0.76)$ & \\
\hline
\end{tabular}

Our study has several limitations. First, this is a singlecentered, retrospective observational study subject to inherent biases including unmeasured confounding, selection, and ascertainment bias. Second, the patients enrolled in the study have different fracture types, femoral neck fractures (Garden III-IV), intertrochanteric fractures (Evans-JensenI-V); it is possible that complex fractures may affect the final result, associated with an increase in operation time and a higher postoperative morbidity. Third, we identified potential DVT cases on the basis of clinical features, e.g. lower extremity swelling, pain, stiffness, superficial venous congestion, and increase in skin temperature, without performing routine angiography or color Doppler ultrasonography in all patients. This may have resulted in failure to detect DVT cases with minimal or no clinical signs [28], thereby reducing the validity of outcome data. Fourth, the sample size of the groups and subgroups is not great. Finally, post-discharge medical record follow-up was imperfect, therefore, it is possible that some venous thromboembolism events may have occurred after hospital discharge and were missed.

\section{Conclusions}

Although early initiation of anticoagulation therapy is always regarded as more effective in reducing risk of VTE, and postoperative initiation of anticoagulation therapy is considered safer than preoperative initiation, the above results indicate that preoperative initiation of anticoagulation therapy with LMWH may not increase intraoperative or postoperative risk of bleeding, but also does not significantly reduce the risk of postoperative DVT or PE, compared to postoperative initiation. Our study may provide a reference in choosing the appropriate methods to prevent the perioperative venous thromboembolism, but further studies with more accurate diagnostic methods may pave the way for evidence-based intervention in this regard.

\section{Abbreviations \\ LMWH: Low-molecular-weight heparin; DVT: Deep venous thrombosis; PE: Pulmonary embolism; VTE: Venous thromboembolism; ACCP: American College of Chest Physicians.}

\section{Competing interests}

We have no conflicts of interest.

\section{Authors' contributions}

LZ and HX conceived and led the study, contributed to the final interpretation, abstracted and arbitrated quality data, and wrote the first draft of the manuscript. NH was involved in drafting the manuscript and revising it critically. ZF and TW proposed many valuable suggestions and measures for improving the process and helped to draft the manuscript. DZ participated in the design of the study and performed the statistical analysis. BJ contributed to the study design, arbitrated studies for inclusion, and commented on successive drafts of the manuscript. All authors read and approved the final manuscript. 


\section{Acknowledgements \& Funding}

Thank Hao Lu, Jian Xiong, Yu Dang, Feng Xue, Jianhai Chen, Ming Yang, Jing Zhou, Yanhua Wang for their kind help and Peixun Zhang for guidance. This research project was funded by the Chinese National Ministry of Science and Technology 973 Project Planning (No. 2014CB542206), the ministry of education innovation team (IRT1201), the National Natural Science Fund (31271284, 31171150, 81171146, 31471144, 30971526, 31100860, 31040043, 31371210, 81372044).

Received: 4 February 2015 Accepted: 2 February 2016

Published online: 12 February 2016

\section{References}

1. Geerts WH, Bergqvist D, Pineo GF, Heit JA, Samama CM, Lassen MR, et al. Prevention of venous thromboembolism: American College of Chest Physicians Evidence-Based Clinical Practice Guidelines (8th Edition). Chest. 2008;133(6 Suppl):381S-453S.

2. Falck-Ytter Y, Francis CW, Johanson NA, Curley C, Dahl OE, Schulman S, et al. Prevention of VTE in orthopedic surgery patients: Antithrombotic Therapy and Prevention of Thrombosis, 9th ed: American College of Chest Physicians Evidence-Based Clinical Practice Guidelines. Chest. 2012;141(2 Suppl):e278S-325S

3. Meza RG, Esquivel GR, Martinez DCSA, Espinosa-Larranaga F, Martinez GM, Torres GR, et al. Prophylaxis of venous thromboembolic disease in high-risk orthopedic surgery. Gac Med Mex. 2012;148(2):144-52.

4. Dahl OE, Quinlan DJ, Bergqvist D, Eikelboom JW. A critical appraisal of bleeding events reported in venous thromboembolism prevention trials of patients undergoing hip and knee arthroplasty. J Thromb Haemost. 2010;8(9):1966-75.

5. Hull RD, Pineo GF, Stein PD, Mah AF, Macisaac SM, Dahl OE, et al. Timing of initial administration of low-molecular-weight heparin prophylaxis against deep vein thrombosis in patients following elective hip arthroplasty: a systematic review. Arch Intern Med. 2001;161(16):1952-60.

6. Perka C. Preoperative versus postoperative initiation of thromboprophylaxis following major orthopedic surgery: safety and efficacy of postoperative administration supported by recent trials of new oral anticoagulants. Thromb J. 2011;9:17.

7. Kalyani BS, Roberts CS. Low molecular weight heparin: current evidence for its application in orthopaedic surgery. Curr Vasc Pharmacol. 2011;9(1):19-23.

8. Hull RD, Pineo GF, Macisaac S. Low-molecular-weight heparin prophylaxis: preoperative versus postoperative initiation in patients undergoing elective hip surgery. Thromb Res. 2001;101(1):V155-62.

9. Borgen PO, Dahl OE, Reikeras O. Preoperative versus postoperative initiation of dalteparin thromboprophylaxis in THA. Hip Int. 2010;20(3):301-7.

10. Knesek D, Peterson TC, Markel DC. Thromboembolic prophylaxis in total joint arthroplasty. Thrombosis. 2012;2012:837896.

11. Raskob GE, Hirsh J. Controversies in timing of the first dose of anticoagulant prophylaxis against venous thromboembolism after major orthopedic surgery. Chest. 2003;124(6 Suppl):379S-85S.

12. Zufferey P, Laporte S, Quenet S, Molliex S, Auboyer C, Decousus H, et al. Optimal low-molecular-weight heparin regimen in major orthopaedic surgery. A meta-analysis of randomised trials. Thromb Haemost. 2003;90(4):654-61.

13. Strebel N, Prins M, Agnelli G, Buller HR. Preoperative or postoperative start of prophylaxis for venous thromboembolism with low-molecular-weight heparin in elective hip surgery? Arch Intern Med. 2002;162(13):1451-6.

14. Della RG, Biggi F, Grossi P, Imberti D, Landolfi R, Palareti G, et al. Italian intersociety consensus statement on antithrombotic prophylaxis in hip and knee replacement and in femoral neck fracture surgery. Minerva Anestesiol. 2011;77(10):1003-10.

15. Caprini JA. Risk assessment as a guide for the prevention of the many faces of venous thromboembolism. Am J Surg. 2010;199(1 Suppl):S3-S10.

16. Pedersen AB, Sorensen HT, Mehnert F, Overgaard S, Johnsen SP. Risk factors for venous thromboembolism in patients undergoing total hip replacement and receiving routine thromboprophylaxis. J Bone Joint Surg Am. 2010;92(12):2156-64

17. Jacobs JJ, Mont MA, Bozic KJ, Della VC, Goodman SB, Lewis CG, et al. American Academy of Orthopaedic Surgeons clinical practice guideline on: preventing venous thromboembolic disease in patients undergoing elective hip and knee arthroplasty. J Bone Joint Surg Am. 2012;94(8):746-7.
18. Horlocker TT. Low molecular weight heparin and neuraxial anesthesia Thromb Res. 2001;101(1):V141-54.

19. Rowlingson JC, Hanson PB. Neuraxial anesthesia and low-molecular-weight heparin prophylaxis in major orthopedic surgery in the wake of the latest American Society of Regional Anesthesia guidelines. Anesth Analg. 2005;100(5):1482-8.

20. Schulman S, Kearon C. Definition of major bleeding in clinical investigations of antihemostatic medicinal products in non-surgical patients. J Thromb Haemost. 2005;3(4):692-4.

21. Lassen MR, Gallus A, Raskob GE, Pineo G, Chen D, Ramirez LM. Apixaban versus enoxaparin for thromboprophylaxis after hip replacement. N Engl J Med. 2010;363(26):2487-98

22. Piovella F, Wang CJ, Lu H, Lee K, Lee LH, Lee WC, et al. Deep-vein thrombosis rates after major orthopedic surgery in Asia. An epidemiological study based on postoperative screening with centrally adjudicated bilateral venography. J Thromb Haemost. 2005;3(12):2664-70.

23. Warwick D. New concepts in orthopaedic thromboprophylaxis. J Bone Joint Surg (Br). 2004;86(6):788-92.

24. Hull RD, Brant RF, Pineo GF, Stein PD, Raskob GE, Valentine KA. Preoperative vs postoperative initiation of low-molecular-weight heparin prophylaxis against venous thromboembolism in patients undergoing elective hip replacement. Arch Intern Med. 1999;159(2):137-41.

25. Kang BJ, Lee YK, Kim HJ, Ha YC, Koo KH. Deep venous thrombosis and pulmonary embolism are uncommon in East Asian patients after total hip arthroplasty. Clin Orthop Relat Res. 2011;469(12):3423-8.

26. Mont M, Jacobs J, Lieberman J, Parvizi J, Lachiewicz P, Johanson N, et al. Preventing venous thromboembolic disease in patients undergoing elective total hip and knee arthroplasty. J Bone Joint Surg Am. 2012;94(8):673-4.

27. Warwick D, Rosencher N. The "critical thrombosis period" in major orthopedic surgery: when to start and when to stop prophylaxis. Clin Appl Thromb Hemost. 2010;16(4):394-405.

28. Samama CM, Ravaud P, Parent F, Barre J, Mertl P, Mismetti P. Epidemiology of venous thromboembolism after lower limb arthroplasty: the FOTO study. J Thromb Haemost. 2007;5(12):2360-7.

\section{Submit your next manuscript to BioMed Central and we will help you at every step:}

- We accept pre-submission inquiries

- Our selector tool helps you to find the most relevant journal

- We provide round the clock customer support

- Convenient online submission

- Thorough peer review

- Inclusion in PubMed and all major indexing services

- Maximum visibility for your research

Submit your manuscript at www.biomedcentral.com/submit
Biomed Central 